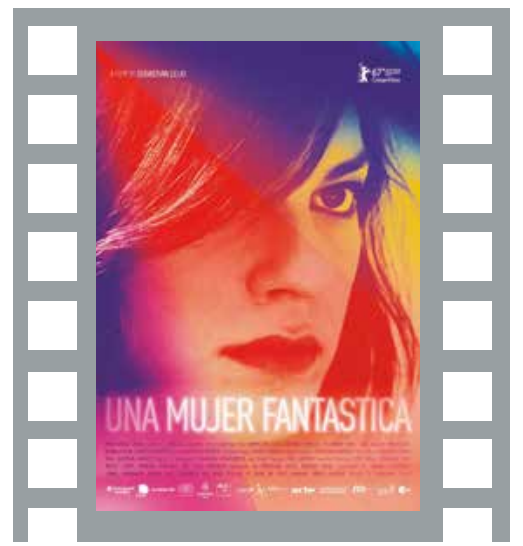

\section{Ficha têcnica}

Título original: Una mujer fantástica

Nacionalidad: Chile

Dirección: Sebastián Lelio

Guion: Sebastián Lelio, Gonzalo Maza

Productora: Co-production Chile-España; Fabula, Komplizen Film, Setembro Cine

Año: 2017

Interpretación: Marina Vidal (Daniela Vega): Orlando (Francisco Reyes): Luis Gnecco (Gabo); Sonia (Aline Küppenheim); Gastón, novio de Wanda (Nestor Cantillana): Adriana, detective (Amparo Noguera): Doctor (Alejandro Goic); Alessandra (Antonia Zegers); profesor de piano (Sergio Hernández); Bruno (Nicolás Saavedra); familiar de Orlando (Marcial Tagle); Pablo (Pablo Cerda); pariente joven de Bruno (Pablo Greene); carabinero (Erto Pantoja); Wanda Vidal (Trinidad González); funcionaria capilla (Paulina Hunt); enfermera (Paola Lattus); masajista (Cristián Chaparro): trabajadora en el velatorio (Bárbara Mundt)

Música: Matthew Herbert

Fotografía: Benjamín Echazarreta

Género: Drama, transexualidad, transgero

Duración: 104 minutos

Premios: 2018 | Premios Oscar: mejor película de habla no inglesa; Festival de Berlín: mejor guion; Globos de Oro: nominada a mejor película de habla no inglesa; Premios Goya: mejor película hispanoamericana; Premios Independent Spirit: mejor película extranjera; National Board of Review (NBR): mejores películas extranjeras del año. Premio mejor película iberoamericana; nominada al Premio PLATINO a los valores cinematográficos y educativos

Trailer: https://www.filmaffinity.com/es/evideos.php?movie_id=750940

\title{
Una mujer fantástica
}

respeto y amor.

Carl R. Rogers

Antonio Machuca Ahumada y Carmen Pereira Domínguez machuca.caronte@gmail.com y mcdguez@uvigo.es

\section{la historia}

Marina es una joven que trabaja como camarera. Le apasiona la música y en sus ratos libres canta en un club nocturno. Orlando, 20 años mayor que ella, es propietario de un negocio textil. Marina y Orlando están enamorados y proyectan un futuro en común. Después de una grata noche celebrando el cumpleaños de Marina, Orlando se siente indispuesto. Ella lo lleva al hospital, pero una vez allí Orlando fallece de un aneurisma cerebral. Marina, aturdida, se marcha rápido pues solo desea sobrellevar la pérdida en la mayor intimidad. No obstante, su vida se complicará al convertirse en sospechosa por la muerte de su pareja. Por ello, una detective la investiga. Además, Marina tendrá que pelear contra los prejuicios de la familia de Orlando que la rechaza por su condición de mujer transexual y le impide asistir al funeral. El hijo mayor de Orlando la intimida y obliga a abandonar el apartamento. Marina tendrá que pelear por sus derechos y demostrar que es una mujer profunda, fiel, fuerte, pasional, honesta, sensible y fantástica.

\section{Temas}

Acoso

Duelo

Educación emocional

Empatía

Familia

Homofobia

Identidad de género

Identidad sexual

Resiliencia

Tabúes y prejuicios

\section{Valores}

Afectividad
Autoestima
Ayuda
Comprensión
Dignidad
Diversidad
Fortaleza
Respeto
Tenacidad
Tolerancia

\section{(r.) Antes de ver la película}

1. Pensamos en las implicaciones que conlleva ser una persona discriminada por su identidad sexual, color de piel, edad, religión, ideología. ¿Cómo contempla este aspecto la Declaración de los Derechos Humanos? Investigamos sobre declaraciones que amparan a la persona de estas exclusiones. https://dudh.es/declaracion-universal-de-derechos-humanos/

2. La diversidad sexual se refiere a la posibilidad que tiene una persona de vivir su orientación sexual e identidad de género de una manera libre y responsable. https://www.mscbs.gob.es/ciudadanos/ enfLesiones/enfTransmisibles/sida/docs/GlosarioDiversidad.pdf

3. Las personas transgénero se enfrentan, a diario, a una discriminación basada en su identidad de género y a violaciones de sus derechos humanos como el derecho a la integridad física, el derecho a la libertad de expresión o el derecho a la vida. Nos informamos de organismos que denuncian estos hechos como Amnistía Internacional. https://www.es.amnesty.org/en-que-estamos/temas/ diversidad-afectivo-sexual/
4. Averiguamos sobre asociaciones y la labor de asesoramiento a personas transexuales y a sus familias como Chrysallis y Naizen https:// www.guiaongs.org/directorio/ongs/chrysallis/; https://naizen.eus/

5. El siguiente documental trata el tema de la transexualidad en menores de edad, donde se expone la vida de estos niños y niñas y de sus familias (Documentos TV: El sexo sentido, 2007). http://www. educatolerancia.com/Igtbifobia-videos/

6. El diccionario de la Real Academia Española de la Lengua define el término resiliencia como la capacidad humana de asumir con flexibilidad situaciones límite y sobreponerse a ellas. Buscamos más información sobre la resiliencia.

7. Asimismo, indagamos acerca de ¿cómo podemos aprender a ser personas resilientes? y ¿qué características deben estar presentes para ello?

8. A continuación, veremos la película, Una mujer fantástica de Sebastián Lelio. Observamos la carátula y pensamos en el título. Un filme recomendado para familias y otras personas, a partir de la adolescencia. 


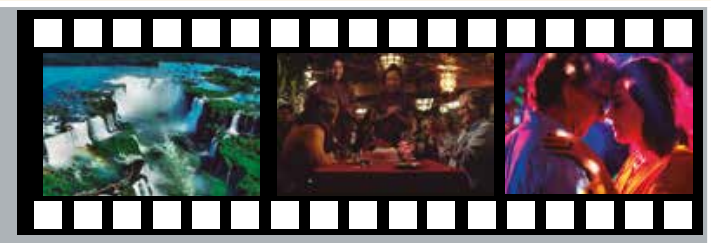

1.1. Después de recrearnos con unas bellas imágenes de la orografía chilena conocemos a Orlando, uno de los protagonistas de filme mientras se relaja en una sauna antes de iniciar la jornada de trabajo en su empresa. Se muestra algo aturdido pues no localiza, ni en su despacho ni en su coche, un sobre blanco (00:01:20 - 00:02:30 y 00:03:44 - 00:04:40)

1.2. Al atardecer, Orlando acude a un pub donde canta su novia Marina, actriz principal de la película. Después de su actuación y con motivo de su cumpleaños, Orlando la sorprende con una cena y un próximo viaje a las cataratas de lguazú. Terminan la velada, bailando en una discoteca (00:05:30 - 00:07:00 y 00:07:07 - 00:09:30 y 00:09:31- 00:09:33)
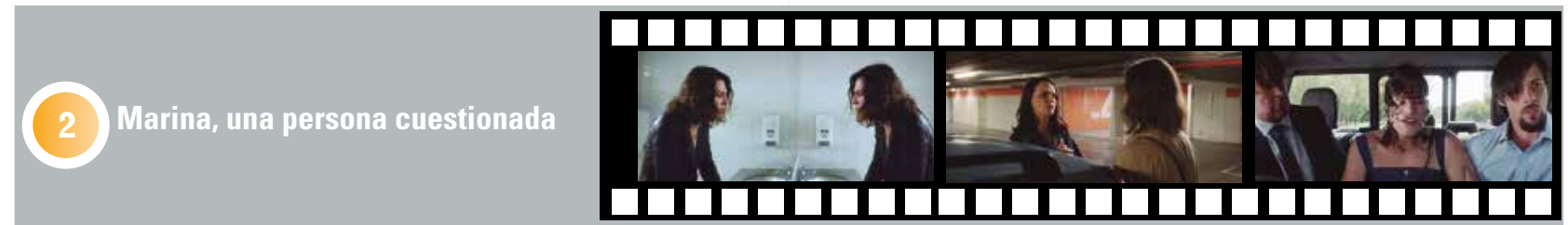

2.1. A media noche, Orlando despierta porque se siente mal y Marina lo lleva rápido a la clínica, pero al poco tiempo fallece de un aneurisma. Marina llama a Gao, el hermano de Orlando, para notificarle lo sucedido; luego, impactada sale apurada del hospital. Pero pronto regresa al hospital y la interroga la policía en la recepción cuestionando su identidad y acciones previas al accidente de Orlando "¿Usted es un familiar?... Su nombre, ¿es un apodo?" Después le solicitan su DNI y le insisten en el nombre legal diciendo, "Usted no está retenido" (00:12:04 - 00:18:12 y 00:19:26 - 00:20:43 y 00:22:10 - 00:24:35).

2.2. Bruno, el hijo de Orlando, entra en el apartamento de su padre que compartía con su pareja. Lo registra y al ver a Marina medio dormida le replica, en un tono verbal sarcástico. Hace comentarios como, "ies que no entiendo qué eres!". Luego, antes de marcharse la intimida y dice, "inncreíble, mi papá estaba loco!" (00:39:21 - 00:40:25).

2.3. Sonia, la exmujer de Orlando, revisa el automóvil de Orlando entregado por Marina en el aparcamiento acordado. Luego intenta enfrentar a Marina y, en un tono defensivo y sutilmente violento, le espeta, "yo pienso que, en esto de verdad, hay pura perversión, cuando te veo, no sé lo que veo. Una quimera veo". Marina le dice "Usted es normal. Usted está bien". Y sobre el deseo de Marina de asistir al funeral le dice, "Daniel, ino vas a ir al funeral y a ninguna parte...!" (00:45:19 - 00:47:10 y 00:48:00 - 00:49:33).

2.4. Marina vuelve a su trabajo y al rato recibe la visita de la detective Cortés, especialista en temas de abuso sexual y resolución de crímenes. Le muestra fotos de Orlando con hematomas sufridos durante su caída comentando que está preocupada por el tema. Por ello, Marina debe demostrar su inocencia y presentarse en la policía para que un médico la fotografíe e inspeccione desnuda (00:49:57 - 00:54:13).
1.1. Describimos las imágenes presentadas antes del título de la película, ¿cómo nos sentimos viéndolas?, ¿por qué se vinculan a esta película? Igualmente, comentamos la música que acompaña a esta secuencia. ¿Qué tonos predominan mientras Orlando recibe los masajes? ¿Qué puede estar pensando Orlando mientras busca el sobre? ¿Le pasará algo?

1.2. Comentamos estas escenas sobre la celebración del cumpleaños de Marina, ¿cómo es la ambientación?, ¿cómo se muestran? Exponemos las dudas surgidas. edades tienen? ¿Cómo se comportan y viven? ¿En qué trabajan? valores destacamos en ellos?
¿Cómo son físicamente Orlando y Marina? Los describimos. ¿Qué ¿Qué aficiones tienen? ¿Qué tipo de relación mantienen? ¿Qué vuelve de nuevo al hospital? ¿A qué responden estas acciones de rechazo y exclusión? ¿Por qué el médico y el policía dudan de ella? ¿A qué pueden obedecer estas actuaciones? Comentad cómo creéis que se siente Marina.

Precisamos el tono de estos interrogantes. ¿Cuál es la respuesta y actitud de ella? ¿Qué matiza específicamente sobre el DNI? ¿Cómo es el trato de Gao hacia Marina? ¿Qué alega sobre ella a la policía? ¿Qué interpretación podemos hacer sobre todo lo ocurrido?

2.2. Describimos este tipo de rechazo y forma de proceder de Bruno hacia Marina. ¿Qué normas está incumpliendo? Destacamos la actitud de Marina ante las críticas del joven. La marginación es un procedimiento que se caracteriza por separar, excluir a la otra persona. Alguien que generalmente pertenece a una minoría, se aparta al diferente. ¿Qué tipo o tipos de marginación podemos observar hoy día en nuestra sociedad?

2.3. ¿Qué señalamos sobre el tono verbal utilizado por Sonia hacia Marina? ¿y sobre su actitud y comentarios al revisar el coche? Describimos a Sonia: ¿qué gestos corporales adopta?, ¿por qué se comporta así? ¿Cómo se muestra y responde Marina ante lo que escucha? Por último, Sonia le insiste que no acuda al velorio. ¿Qué razones puede haber para esto? ¿Qué destacamos sobre estas actitudes? Describimos y observamos el comportamiento y las expresiones de Marina durante este encuentro.

2.4. Hablamos del trabajo de Marina: su forma de ejercerlo, su relación con los compañeros y el trato con su propietaria. Describimos a la policía Cortés que investiga a Marina, ¿cómo se comporta Marina y qué le responde?

Analizamos la exploración médica que debe pasar Marina, iqué dice la comisaria? ¿Cómo trata el doctor a Marina y qué le cuestiona? ¿Cómo vive ella esos momentos? ¿Qué planos vemos? ¿Qué sentimos ante esta escena?
2.1. ¿Cómo procede Marina ante el estado crítico de Orlando? ¿Por qué 
2.5. Marina llega a la iglesia del tanatorio donde está Orlando, pero es expulsada e insultada y una mujer la obliga a salir del lugar. Más tarde, el hijo de Orlando y sus primos la persiguen, insultan y la suben al coche donde le envuelven la cabeza con cinta adhesiva. Terminan echándola del automóvil y dejándola en un callejón. Luego Marina, ausente, camina sin rumbo y entra en un club nocturno (01:02:56 - 01:04:04 y 01:05:09 - 01:33:55 y 01:08:16 y 01:08:41 - 01:12:05).
2.5. Primero aparecen los insultos y luego se evidencia un acto violento Reflexionamos sobre esas formas de reaccionar ante la presencia de Marina en la iglesia. ¿Qué se intenta acallar al tapar su boca y rostro? ¿Qué mecanismos generan la respuesta violenta y los gestos de odio? ¿Por qué este comportamiento marginal hacia un cuerpo diverso? ¿De qué se evade Marina? ¿A quién ve constantemente? ¿Qué siente? Interpretamos el baile final en el local nocturno.

\section{Mi nombre es Marina, ¿hay algún problema con eso?}

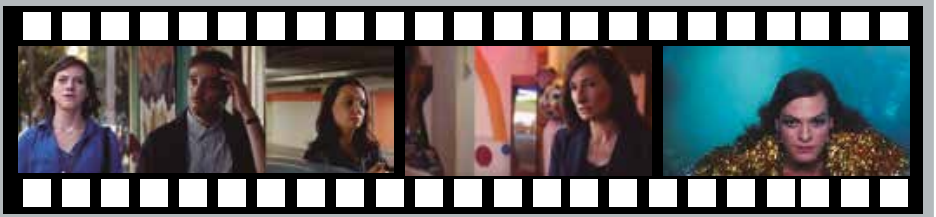

3.1. Marina, responde de esta manera ante los diversos interrogatorios por los que pasa. Se presenta una amalgama de cuestiones y dudas sobre ella. Se encuentra una y otra vez con el rechazo de quienes no la aceptan. La quieren dejar fuera del velatorio, del entierro y de sus vidas. La exesposa, la familia, la policía, todos en el entorno la rechazan, cuestionan su condición sexual.

\section{A contraviento}

3.1. Ante esta forma de reaccionar del entorno de Marina, donde pocos la cobijan o respetan su forma de ser, ide qué modo procede la protagonista ante estos embates? ¿Cuál o cuáles son sus mecanismos de defensa? ¿Qué podemos señalar respecto de su actitud? Señalamos a quienes comprenden y amparan a Marina. ¿Qué desea transmitir el director de la película con esta línea de narración?

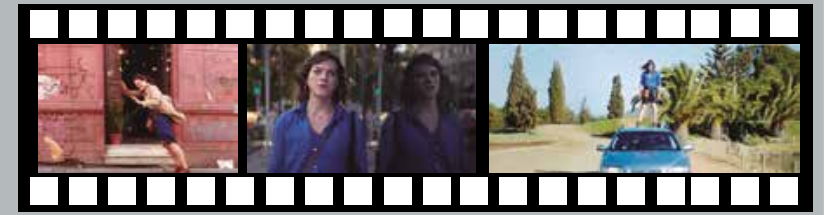

4.1. En varios momentos, la fuerza de la naturaleza hace su aparición en el metraje, unas cataratas, una lluvia intensa o un fuerte viento. Son los elementos externos que debe hacer frente la protagonista. En una escena esencial del argumento, después de visitar a su profesor de canto lírico, Marina camina por la calle y lucha contra el ímpetu de un viento huracanado, igualmente, oímos la ópera de fondo, Sposa Son Disprezzata, interpretada por ella (00:58:13 - 00:59:22)

4.2. Marina abandona el apartamento de Orlando para alojarse en casa de su hermana Wonda y su pareja Gaston. Mientras desayunan hablan sobre la esquela de Orlando en el periódico. Marina afirma que no asistirá al acto y que ya ha pasado página a todo lo sucedido (01:13:35 - 01:15:19).

4.3. La familia de Orlando, su exesposa, su hijo, su entorno, le insisten a Marina que no asista al funeral. Argumentan que ella no tiene espacio allí, además, es una ceremonia privada. En contra del criterio y deseos de la familia, la protagonista asiste también al tanatorio provocando tensas reacciones especialmente en Sonia y Bruno. Poco después Marina los desconcierta y asusta reivindicando a su perra Diabla (01:23:33 - 01:24:55).

4.1. En esta escena de tono poético y expresivo, ¿qué podemos señalar en referencia a esta narración? ¿Qué busca expresar el realizador en esta escena? ¿Qué es lo que intenta detener Marina? ¿Qué fuerzas externas la presionan? ¿Cuáles le permitirán validarse y seguir a contracorriente? ¿Por qué visita a su profesor de canto y qué le aconseja? ¿Qué razones nos permiten señalar a Marina como mujer fantástica?

4.2. ¿Qué le dice Wonda a Marina al encontrarse? ¿Qué siente por ella? ¿Qué comentarios se producen entre su hermana y novio por alojar a Marina? ¿Qué alega Marina? ¿Qué tensiones se crean entre ellos al leer la esquela y cómo cierra el tema Marina?

4.3. La exesposa le grita a Marina "iCórrete, loco de mierda!". Su cuñado Gao matiza con tolerancia, "iSonia, es mujer!". ¿Qué pensamos de esas frases y reacciones? Marina, sube al techo del coche y patalea con furia pidiendo la entrega de su perra. Describimos a Diabla y su importancia para Marina. ¿Por qué esa insistencia en conseguir a su perra? ¿Es una forma de aferrarse y mantener un vínculo con los afectos de Orlando?

\section{Después de la despedida, la vida sigue}

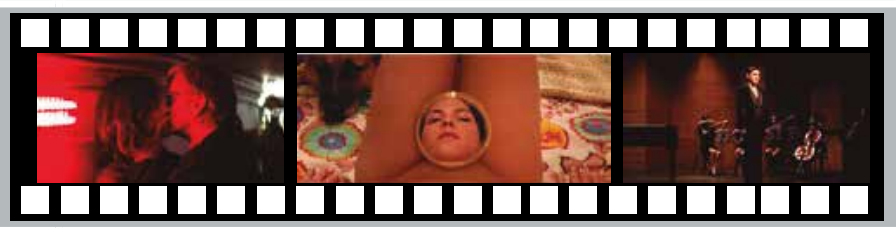

5.1. Pasados los diversos rechazos y reacciones de la familia, Marina consigue un momento a solas y así puede despedirse de Orlando, poco antes de su incineración. Tras un largo devenir de enfrentamientos logra ese espacio y tiempo en completa soledad e intimidad con quien compartió una inolvidable relación afectiva (01:28:08 - 01:30:27).

5.2. Marina debe continuar la vida apoyándose en los valores aprendidos de su relación con Orlando. A menudo ella hace deporte, acompañada de su perra Diabla, por una zona natural de la ciudad de Santiago de Chile. Asimismo, ha retomado sus clases de canto lírico (01:30:28 - 01:31:42).

La película finaliza con Marina en el escenario de un auditorio donde interpreta Ombra Mai Fu y deleita a un público con su prodigiosa voz (01:32:37 - 01:34:50).
5.1. En el argumento, la protagonista realiza un viaje complejo, difícil, lleno de dificultades, arbitrariedades, rechazos, denostaciones que en ningún caso amilanan su tesón. ¿Qué podemos señalar sobre este periplo existencial y vivencial? ¿Qué reflexiones extraemos de esta escena? ¿De qué modo Marina pudo superar las múltiples barreras que le impedían esa despedida?

5.2. ¿En qué aficiones se ampara Marina y cuándo recurre a ellas? Señalamos los diversos momentos de la película donde Marina se mira al espejo, ¿qué interpretaciones hacemos de cada una de esas imágenes? ¿Qué ha aprendido Marina de su relación con Orlando? Señalamos las cualidades que tiene Marina. ¿Qué valoraciones otorgamos al momento final del filme mientras contemplamos y escuchamos a la protagonista? ¿Cómo nos hemos sentido viendo esta película? ¿Qué hemos aprendido de ella? 
1. El director Sebastián Lelio al recibir el Oscar 2018 a la mejor película extranjera por Una Mujer Fantástica, lo distingue como el primer chileno en conseguir este premio.

2. Sebastián Lelio Watt nació en la ciudad argentina de Mendoza en 1974, aunque se siente chileno pues desde niño vivió en Viña del Mar. También residió en lugares como Norteamérica y actualmente en Berlín. Es un realizador, guionista, productor y montajista. Tras iniciar Periodismo en la Universidad de Andrés Bello cursó estudios de cine en la Escuela de la Universidad de ARCIS, en 1994. Un año después, ingresó en la Escuela de Cine de Chile. Asimismo, ha sido distinguido con la Beca Guggenheim.

3. En sus trabajos prioriza la tecnología digital. Ha dirigido cortometrajes y videos musicales. Entre sus largometrajes destacan: $L a$ sagrada Familia (2006), Navidad (2010), Gloria (2013), Una mujer fantástica (2017) y Desobedience (2018).

https://es.wikipedia.org/wiki/Sebasti\%C3 \%A1n_Lelio
4. Daniela Vega, protagonista de Una Mujer Fantástica, fue la primera transexual en ganar un Oscar, por esta película. En su documento de identidad aún figura su nombre de varón. Además es cantante de ópera.

5. Esta película de Sebastián Lelio es el cuarto largometraje chileno en ganar el premio Goya a la mejor película Iberoamericana. Previamente lo hicieron La Frontera, de Ricardo Larraín, en 1990, La buena vida, de Andrés Wood, en 2008 y La vida de los peces, de Matías Bize, en 2010.

6. La empatía, la verdad moral y la sensibilidad han sido centros de interés del guion elaborado entre Sebastián Lelio y Gonzalo Mazo que da vida a esta película basada en el amor y la pérdida.

\section{Actividades de enperiencia, reflekión y acción en común}

1. Retomamos la frase de Carl Rogers que introduce esta guía de cine "Una persona, al descubrir que es amada por ser como es, no por lo que pretende ser, sentirá que merece respeto y amor" la relacionamos con Una mujer fantástica y exponemos nuestras consideraciones.

2. El título Una mujer fantástica nos presenta de algún modo una ambigüedad. Podemos interpretar que el adjetivo fantástico adosado al sustantivo mujer puede denotar una cualidad suprahumana, fuera de lo común; por otra parte, connota la fantasía, aquella mujer que no existe. ¿Qué interpretación hacemos de ello, entonces?

3. La banda sonora del filme ha sido creada por el compositor y productor británico Matthew Herbert, indagamos sobre su trayectoria profesional y valoramos su trabajo en Una mujer fantástica. Para ello, ofrecemos los siguientes enlaces:

https://www.clubbingspain.com/artistas/uk/matthew-herbert.html https://bsomagazine.com/2018/04/06/matthew-herbert-a-fantastic-woman-2017/

http://www.maintitles.net/reviews/una-mujer-fantastica/

4. En la escena donde Marina conduce el coche para entregárselo a Sonia escuchamos parte de la famosa canción $A$ natural woman (1967) de Aretha Franklin. La oímos prestando atención a su letra y la vinculamos con la película.

http://www.saberingles.com.ar/songs/177.html

5. Daniela Vega, la protagonista de Una mujer Fantástica, al recibir el premio Goya 2018, señaló: "Rebeldía, resistencia y amor". Conocemos la historia de vida de esta actriz y damos sentido a esas tres palabras.

https://www.youtube.com/watch?v=6RR_0G05gkY\&t=31s
6. El director Sebastián Lelio afirma, “Concibo, Una mujer fantástica, como una película de esplendor estético, de vigor narrativo, de tensión y emoción. Politonal, multiexperiencial, multiemocional. Una película que es, al mismo tiempo, exaltación y examen de su personaje central: Marina Vidal". ¿De qué manera nos ilumina Lelio sobre la tolerancia? También recomendamos estos enlaces: Una mujer fantástica, making of

https://www.youtube.com/watch?v=y2D3qMEDc00

Entrevista a Santiago Lelio

https://cinechile.cl/entrevistas/entrevista-a-sebastian-lelio-director-de-una-mujer-fantastica/

7. Sugerimos otros filmes de temática similar: Mi vida en rosa, A. Berliner (Bélgica, 1997); Boys Don't Cry, K. Peirce (EE. UU., 1999); El vestido nuevo, S. Pérez (España, 2007); Tomboy, C. Sciamma (Francia, 2011); La chica danesa, T. Hooper (Reino Unido, 2015); Close-Knit, N. Ogigami (Japón, 2017); Girl, L. Dhont (Bélgica, 2018); Una niña, S. Lifshitz (Francia y Dinamarca, 2020)). Si conocéis otros, señaladlos.

8. Finalmente, a modo orientativo, leemos las siguientes críticas cinematográficas a Una mujer fantástica con la intención de que elaboréis vuestro propio juicio de valor a la película.

https://cinechile.cl/criticas-y-estudios/una-mujer-fantastica-desebastian-lelio/

https://www.espinof.com/criticas/una-mujer-fantastica-hermosaradiografia-de-la-diversidad-femenina-con-una-daniela-vegaextraordinaria 